\title{
Erratum to: Biowaste Reuse Through Composting: The Response of Barangay Holy Spirit in Quezon City, Philippines, to Solid-Waste Management
}

\author{
Armando Palijon, Yuji Hara, Akinobu Murakami, Constancio De Guzman,
} and Makoto Yokoyari

(C) Springer Japan 2017

M. Yokohari et al. (eds.), Sustainable Landscape Planning in Selected Urban

Regions, Science for Sustainable Societies, DOI 10.1007/978-4-431-56445-4_19

\section{DOI 10.1007/978-4-431-56445-4_22}

In Chapter 19 titled "Biowaste Reuse Through Composting: The Response of Barangay Holy Spirit in Quezon City, Philippines, to Solid-Waste Management", the name of the author is incorrect.

The name should be Makoto Yokohari on the online and print version.

The author name is also updated in the Table of Contents of the Frontmatter.

The updated original online version for this chapter can be found at http://dx.doi.org/10.1007/978-4-431-56445-4_19 